\title{
O uso de textos filosóficos em sala de aula: o que os professores pensam sobre isso?
}

\author{
The use of philosophical texts in the classroom: what do teachers think about it?
}

\author{
Fábio Antonio Gabriel \\ Professor Doutor no Colégio Estadual Rio Branco, Santo Antônio da Platina, Paraná, Brasil. \\ fabioantoniogabriel@gmail.com \\ Orcid: https://orcid.org/0000-0002-4990-4102
}

\section{Ana Lúcia Pereira \\ Professora na Universidade Federal de Ponta Grossa, Ponta Grossa, Paraná, Brasil. ana.lucia.pereira.173@gmail.com \\ Orcid: https://orcid.org/0000-0003-0970-260X}

Recebido em 19 de junho de 2019

Aprovado em 07 de outubro de 2019

Publicado em 07 de janeiro de 2020

RESUMO: Este artigo tem como objetivo analisar as percepções de professores de Filosofia em serviço sobre o uso de textos dos filósofos em sala de aula. O referencial teórico está relacionado à compreensão do papel da Filosofia na sociedade segundo Jaspers (1971) e a importância do uso de textos filosóficos em sala de aula. A pesquisa é de natureza qualitativa e os sujeitos são 32 professores de Filosofia da rede pública do Estado do Paraná, Brasil. Os dados foram coletados por meio de questionários e organizados e analisados por intermédio da análise de conteúdo, de onde foi possível identificar cinco categorias. Os resultados apontam que as percepções dos professores sobre o uso de textos dos filósofos em sala de aula estão relacionadas às questões sobre o ensino da Filosofia de forma reflexiva, como uma construção histórica e fundamental, para que o aluno viva uma experiência filosófica. Palavras-chave: Ensino de Filosofia; Leitura de textos filosóficos; Experiência filosófica.

ABSTRACT: This paper aims to analyze the perceptions of Philosophy teachers in service about the use of texts of philosophers in the classroom. The theoretical reference is related to the understanding of the role of Philosophy in society according to Jaspers (1971) and the importance of the use of philosophical texts in the classroom. The research is of qualitative nature and the subjects are 32 Philosophy teachers of the public school network of the State of Paraná, Brazil. The data were collected through questionnaires and organized and analyzed through the content analysis, from which it was possible to identify five categories. The results point out that teachers' perceptions about the use of texts of philosophers in the classroom are related to the issues about the teaching of Philosophy in a reflexive way, as a historical and fundamental construction for the student to live a philosophical experience. Keywords: Teaching Philosophy; Reading of philosophical texts; Philosophical experience. 


\section{Introdução}

Desde que a Filosofia foi instituída como disciplina obrigatória nos currículos oficiais no Brasil, seu ensino tem se caracterizado a partir de embates e discussões entre aqueles que a valorizam e reconhecem a sua importância na formação de nossos jovens, e aqueles que, muitas vezes, não têm sequer uma formação básica filosófica, os quais defendem a ideia de que a Filosofia não serve para nada. Essa questão faz-nos pensar: Por que a Filosofia tem sido tão desprezada na sociedade contemporânea? ${ }^{1}$

Nas últimas décadas, a Filosofia tem lutado para manter o seu lugar como disciplina constitutiva de nossos currículos e importante para a formação crítica de nossos jovens desde o Ensino Médio. Destacamos, portanto, a importância da leitura de textos filosóficos em sala de aula seja no Ensino Médio ou no Ensino Superior. Apontamos, ainda, a relevância de trabalharem-se os conceitos filosóficos a partir dos próprios textos dos filósofos, pois a utilização de comentadores contribui em muito para entender o pensamento dos filósofos, mas não basta. Nesse sentido, acreditamos que é necessário ter o contato direto com a argumentação do filósofo em seu texto original. Assim sendo, defendemos a ideia do filosofar a partir dos próprios filósofos.

Nesse contexto, este artigo tem como objetivo analisar as percepções de professores de Filosofia em serviço sobre o uso de textos dos filósofos em sala de aula. Como opção de processo de escrita, organizamos o artigo em quatro seções, além desta introdução e das considerações finais. Na primeira seção, apresentamos uma compreensão da própria Filosofia, com Karl Jaspers (1971), e o quanto a Filosofia é desprezada em diversos contextos, justamente porque provoca o pensamento e a crítica. Além disso, amparamonos, também, na compreensão de experiência filosófica. Na segunda seção, procuramos elencar uma breve revisão de literatura sobre a leitura de textos filosóficos em sala de aula, em busca de evidenciar as perspectivas que são apontadas por diversos autores sobre o ensino de Filosofia e a leitura de textos filosóficos. Nos artigos, destaca-se a utilização de textos filosóficos em sala de aula e de metodologias diversas como o mapa conceitual para atingir um ensino de Filosofia profícuo. Na terceira seção, descrevemos os pressupostos metodológicos utilizados. Na quarta, apresentamos e discutimos os resultados obtidos.

\section{Contextualizando o ensino de filosofia como disciplina provocadora do pensamento}

Iniciamos nossa reflexão sobre a identidade da Filosofia com uma problematização de Jaspers (1971, p. 139): "Por força da tradição, a Filosofia é polidamente respeitada, mas, no fundo, objeto de desprezo". Talvez, principalmente em uma concepção de ciência positivista, realmente não exista espaço para se pensar nas contribuições da Filosofia para o mundo atual. Pode ser que a Filosofia realmente seja algo que cause transtornos a um pensamento pragmatista, que privilegia mais particularmente aquilo que é prático e experimentável em laboratório.

Nesse sentido, concordamos com Jaspers (1971, p. 139) que afirmou que a "[...] opinião corrente é a de que a Filosofia nada tem a dizer e carece de qualquer utilidade prática. É 
nomeada em público - mas existirá realmente? Sua existência se prova, quando menos, pelas medidas de defesa a que dá lugar". A utilidade da Filosofia talvez seja realmente a grande questão que leva a sociedade contemporânea a desvalorizar tal ciência do pensar, ignorando-a porque não seria útil. Entretanto, o que seria a utilidade? Por que não haveria utilidade no pensar, no ensinar e no aprender a pensar? Que tipo de utilidade tem a Filosofia? São questões que devem ser problematizadas filosoficamente, no intuito de sugerir uma reflexão sobre esse entendimento. Jaspers (1971) ajuda-nos a pensar sobre o porquê de tanto desprezo pela Filosofia na contemporaneidade:

\begin{abstract}
Muitos políticos veem facilitado seu nefasto trabalho pela ausência da Filosofia. Massas e funcionários são mais fáceis de manipular quando não pensam, mas tão-somente usam de uma inteligência de rebanho. É preciso impedir que os homens se tornem sensatos. Mais vale, portanto, que a Filosofia seja vista como algo entediante. [...]. Assim, a Filosofia se vê rodeada de inimigos, a maioria dos quais não tem consciência dessa condição. A autoplacência burguesa, os convencionalismos, o hábito de considerar o bem-estar material como razão suficiente de vida, o hábito de só apreciar em função de sua utilidade técnica, o ilimitado desejo de poder, a bonomia dos políticos, o fanatismo das ideologias, a aspiração a um nome literário - tudo isso proclama a antifilosofia. E os homens não o percebem porque não se dão conta do que estão fazendo. E permanecem inconscientes de que a antifilosofia é uma Filosofia, embora pervertida, que, se aprofundada, engendraria sua própria aniquilação. (JASPERS, 1971, p. 140-141).
\end{abstract}

Para o autor, massas de rebanho são muito mais fáceis de dominar. Assim sendo, conforme destacamos na introdução, quando pensamos na Filosofia no Ensino Médio brasileiro, percebemos um movimento constante de entrada e de retirada da disciplina do currículo, o que nos leva a pensar que se instala uma antifilosofia, conforme nos diz Jaspers (1971). Indubitavelmente, a Filosofia no currículo do Ensino Médio proporciona reflexões que produzem um novo perfil ao egresso nessa modalidade de ensino. A presença da Filosofia nessa fase escolar pode contribuir para se pensar em outras formas de pensamento, diferentes daquela que leva apenas a um entendimento homonogeizante. A Filosofia, no Ensino Médio, possibilita que os estudantes saiam de sua caverna, de seus preconceitos, e se abram para a tolerância do que é diferente de si mesmos.

Gabriel (2017) expõe suas ideias ao longo de sua obra resultante de pesquisa de Mestrado sobre o ensino de Filosofia como experiência filosófica, a qual, na perspectiva do autor, seria um passo a mais a ser realizado após a aquisição enciclopédica de conhecimentos filosóficos. O enciclopedismo por si só não basta, porque limita o exercício da Filosofia apenas a receber questões prontas e a memorizar sistemas filosóficos. Para o pesquisador, a experiência filosófica

[...] é um processo vivo em que os pensamentos dos filósofos da tradição são novamente recriados e assumem novas 
perspectivas. E um dos elementos importantes no ensino de Filosofia é despertar para a autonomia; sem autonomia não é possível pensar por si mesmo e nem vislumbrar os horizontes da experiência filosófica. (GABRIEL, 2017, p. 47).

Gabriel (2017) na introdução de sua dissertação, situa o referencial teórico que nos auxilia a pensar a aula de Filosofia como experiência filosófica, que se apoia nos pensamentos de Friedrich Nietzsche, Gilles Deleuze e Félix Guattari. Esses pensadores, segundo Gabriel (2017), contribuem para pensar um ensino de Filosofia no Ensino Médio que seja diverso de uma Filosofia enciclopédica. Trata-se, pois, de problematizar um ensino de Filosofia que venha ao encontro da existência do estudante de Filosofia do Ensino Médio. De Nietzsche (1978), ele busca, sobretudo, o referencial de "avaliar o valor dos valores" como uma possibilidade de os estudantes conhecerem as ideias desse filósofo e constatar o quanto tais conhecimentos podem ser úteis ao cotidiano de sua vida. O filósofo de Sils Maria inova ao problematizar não somente os valores morais, mas em se perguntar qual seria a origem dos valores morais. Ele se pergunta sobre quais forças e quais relações de força desencadearam a existência de determinados valores.

Uma das questões que atravessa a história da Filosofia é se ela seria algo para todos ou apenas para uma minoria eleita e seleta para conhecer tal ciência. Nos dizeres de Jaspers:

\begin{abstract}
Para Platão, poucos homens são aptos para a filosofia e só adquirem tal aptidão após longa propedêutica. Há dois tipos de vida na Terra, disse Plotino, um próprio dos sábios e outro da massa dos homens. Também Espinosa só espera filosofia do homem excepcional. Kant, porém, acredita que a rota por ele traçada pode tornar-se um caminho real: a Filosofia aí está para todos. E seria mau se fôsse diferente. Os filósofos não passam de elaboradores e guardiães de atas, onde tudo deve estar justificado com precisão máxima. (JASPERS, 1971, p. 142).
\end{abstract}

Com a interpretação de Jaspers (1971) sobre o entendimento de Imamnuel Kant, também entendemos que a Filosofia pode ser estudada por todos. Ela não seria um prêmio de alguns que teriam mais capacidade para adentrar nas questões filosóficas. Gramsci, inclusive, como é conhecido, irá mais longe e dirá que todos os homens são filósofos. Realmente, todos os homens são filósofos na medida em que se põem a refletir sobre a sua própria existência e a exercitarem sua autoconsciência sobre o mundo em que estão inseridos. Dito isso, a seguir, trazemos algumas contribuições teóricas sobre a leitura de textos filosóficos.

\title{
Ensino de filosofia e leitura de textos filosóficos
}

Severino (2009) discorre sobre o processo de leitura de textos filosóficos apontando os seguintes momentos: etapa de análise textual; etapa de análise temática; etapa de análise interpretativa; etapa de problematização; etapa de elaboração reflexiva. O autor apresenta 
cada etapa que culmina com a análise interpretativa. Ela é de fundamental importância porque é nela que se instaura um momento crítico.

O autor valoriza de forma acentuada também o momento da problematização e da reflexão pessoal. Enquanto a problematização caracteriza-se por ser um momento ápice da experiência filosófica, porque o leitor aproxima-se de buscar qual é o problema central que está sendo trabalhado pelo filósofo e em que medida aquele problema pode ser atualizado para nossos dias; a reflexão pessoal é um momento final, de grande importância, porque é quando se relaciona o que foi mencionado pelo filósofo àquilo que subjetivamente se valoriza como problema filosófico. Trata-se de uma síntese não somente pessoal, da percepção subjetiva, mas também objetiva, do que foi problematizado por determinado filósofo e aquilo que se relaciona à existência do leitor.

Mendes e Rezende (2013) apresentam a importância da leitura de textos filosóficos nas aulas de Filosofia como atividade propiciadora de um contato direto com os textos de Filosofia. Metodologicamente, os autores apresentam, como caminho, a leitura dos textos utilizando-se de mapas conceituais. Nas palavras dos autores:

\begin{abstract}
O processo de leitura do texto filosófico, por meio da produção e discussão dos mapas conceituais, tanto no plano individual como no coletivo, mediado pelo trabalho docente, constitui-se na produção de materiais empíricos, a partir dos quais é possível avaliar qualitativamente o processo de ensino e aprendizagem, por meio do qual os alunos se apropriam e ressignificam os conceitos filosóficos. Neste processo, os alunos começam a perceber que os conceitos são elementos importantes na construção do conhecimento filosófico. Assim, os materiais produzidos são tomados como um conjunto de documentos que acabam por constituir um dossiê do processo de aprendizagem. (MENDES; REZENDE, 2013, p. 40, grifo nosso).
\end{abstract}

Destacamos a expressão "ressignificam os conceitos filosóficos" justamente para demonstrar que os textos filosóficos não estão mortos, mas, sim, ganham vida a cada leitura. Se o professor de Filosofia se limitar a transmitir conceitos a partir de comentadores, ele inviabiliza essa ressignificação filosófica. É interessante observarmos que os filósofos de todos os tempos, mesmo aqueles que seguiram outros, também passaram por um processo contínuo de ressignificar os conceitos dos próprios mestres. Isso leva à percepção, já conhecida, de que a Filosofia é a arte das perguntas e da busca de sentido para as próprias nuances filosóficas.

Horn e Valese (2012) discutem, em seu artigo, sobre a importância e o lugar do texto filosófico no Ensino Médio. O âmbito da pesquisa retratada é de 228 professores de Filosofia do estado do Paraná. No texto, os autores destacam a importância de uma relação entre Filosofia e existência: "A leitura e sistematização de textos filosóficos para além da inteligibilidade têm ainda outra função: a de permitir com que o estudante possa posicionar-se frente às polêmicas existenciais e problemas sociais e políticos que o cotidiano se Ihes apresenta" (HORN; VALESE, 2012, p. 167). Os pesquisadores concluem que a leitura e a análise de textos filosóficos constituem uma mediação praxiológica dos conteúdos, "[...] 
possibilitando-lhe a superação da consciência passiva e ingênua e, em contraposição, suscitando-Ihe o desenvolvimento de uma consciência crítica" (HORN; VALESE, 2012, p. 175).

\section{O estudo}

Esta pesquisa é de natureza qualitativa (BOGDAN; BIKLEN, 1994), cujos sujeitos são 30 professores de Filosofia da Rede Pública do Estado do Paraná, de diferentes regiões. A coleta dos dados foi realizada por meio de questionário aplicado via Google forms. O questionário era composto por seis questões, que buscavam, além de traçar o perfil dos participantes, investigar as diferentes percepções que professores de Filosofia tinham sobre o uso de texto filosóficos em sala. Entretanto, neste artigo, utilizamos apenas os dados levantados a partir da primeira pergunta, que buscou identificar a percepção dos professores sobre a importância de utilizarem textos de filósofos em sala de aula.

Os dados foram organizados com base na metodologia de análise de conteúdo apresentada por Bardin (2011). Essa técnica auxilia na descrição e na interpretação do conteúdo de documentos e de textos. Dessa forma, a organização e a interpretação dos dados coletados foram organizadas em três momentos principais: pré-análise, exploração do material e posterior tratamento dos resultados.

$\mathrm{Na}$ pré-análise, buscamos identificar, nas falas dos professores, algumas unidades de análises para que pudéssemos caracterizar as percepções dos professores. Na etapa de exploração do material e unitarização dos dados, foram selecionados os trechos do conteúdo das respostas do questionário. Na terceira etapa, o tratamento dos resultados, esses trechos foram classificados e, de acordo com as semelhanças, agrupados em unidades, que dão origem às categorias emergentes dos dados. Por meio desse processo, foi possível identificarmos cinco categorias sobre as percepções dos professores em relação à importância do uso de texto dos filósofos em sala de aula.

\section{Resultados e discussões}

Os principais achados que surgiram a partir das unidades de análise identificadas nas respostas dos professores sobre a importância de utilizarem textos de filósofos em sala de aula nos permitiram evidenciar cinco categorias. Os aspectos pertinentes a essas cinco categorias serão descritos a seguir por meio de uma análise dos resultados e das discussões relacionadas. Nós extraímos os trechos das falas dos professores como evidência de resultados da pesquisa. Para preservar a identidade dos professores, eles serão representados pela letra $\mathrm{P}$ seguida por um número; ou seja, P1 representa o professor 1; P2, o professor 2, e assim sucessivamente.

\section{Categoria I - Aumentar a capacidade de reflexão}

As unidades de análises que deram origem à primeira categoria relacionam o uso de textos dos filósofos em sala de aula como uma possibilidade para aumentar a capacidade de reflexão. 
Desse modo, eles reúnem aspectos que dão significado à aprendizagem da Filosofia de uma forma mais fundamentada e reflexiva, conforme exemplificado nas falas dos professores a seguir:

P1: Ler a fonte traz maior capacidade de reflexão aos alunos.

P5: Aumentar o conhecimento dos alunos sobre a tradição filosófica, abrindo espaço para primeiras reflexões da Filosofia.

P13: O texto filosófico possibilita exercício de fundamentação argumentativa.

P24: Acho que uma compreensão profunda de uma teoria filosófica só é possível a partir do texto do filósofo.

Conforme Jaspers (1971), há diversos questionamentos sobre a utilidade da Filosofia. Ao pensarmos nos textos filosóficos a serem utilizados em sala de aula, podemos entender que as atividades com os textos filosóficos proporcionam um exercício de aprofundamento de interpretação de textos. O texto filosófico não é um texto literário, mas possibilita que o estudante possa investigar de modo mais profundo a arte de argumentar presente nos textos filosóficos.

Pelos dizeres dos participantes da categoria I, entendemos o quanto a leitura dos textos filosóficos possibilita, além do exercício da argumentação, uma reflexão filosófica. Evidentemente, quando se vai aos originais dos textos filosóficos, pode-se perceber a complexidade da argumentação dos filósofos ao expor seus conceitos e suas teorias sobre o mundo e sobre o ser humano.

Gabriel (2017) investiga a importância de que o ensino de Filosofia possibilite essa argumentação e reflexão, que advém justamente da reflexão e da experiência filosófica. Nesse sentido, ler um texto filosófico é caminhar para a experiência do pensamento. Por serem complexos, os textos filosóficos são imprescindíveis à contribuição do(a) professor(a) no momento de lê-lo.

\section{Categoria II - Ensinar a experiência filosófica}

A segunda categoria foi construída a partir de unidades de análise que apontam a importância do uso de textos dos filósofos em sala de aula como uma possibilidade para se ensinar a experiência filosófica, conforme sugerem as falas a seguir:

P9: É importante o aluno ter contato com a linguagem filosófica, forma de escrita, organização das ideias, etc.

P11: Extremamente importante para que não se ensine apenas História da Filosofia, mas que ensine a experiência filosófica.

P26: Importância capital pelo fato de que o núcleo da atividade filosófica são estes textos. Não podemos furtar os alunos destas experiências.

P28: Percepção e experiência de se enfrentar a força de um pensamento conceitual.

As falas desses docentes vão ao encontro do que Gabriel (2017) defende para o ensino de Filosofia, nas aulas de Filosofia como uma experiência filosófica, como um passo a mais a ser realizado após a aquisição enciclopédica de conhecimentos filosóficos. 
Também podemos destacar a fala do professor $\mathrm{P} 11$, que entende o processo da leitura filosófica como momento oportuno para a experiência filosófica. Isso também vai ao encontro do que Severino (2009) apresenta como último momento no exercício da leitura filosófica analítica: a reflexão pessoal, a qual "[...] é uma reflexão conclusiva a respeito de temáticas abordadas no texto e analisadas ao longo da leitura" (SEVERINO, 2009, p. 49). É nessa síntese pessoal realizada que se tem a possibilidade de transformar a Filosofia em existência. Quando pensamos na experiência filosófica, valorizamos uma experiência pessoal, subjetiva, que vem ao encontro da possibilidade de exercitar um pensamento conceitual, como apontou P28 anteriormente. Conforme $\mathrm{P} 26$, devemos possibilitar que os estudantes tenham um contato com essa importante percepção filosófica, que é o relacionamento da Filosofia com a vida das pessoas. Um(a) professor(a), por exemplo, ao ensinar a dúvida metódica de Descartes, precisa possibilitar para seus estudantes que assumam, para a sua própria vida, o método cartesiano para se encontrar com ideias verdadeiras e indubitáveis.

\section{Categoria III - Possibilitar o contato com o pensamento do filósofo}

As unidades de análise que deram origem à terceira categoria apontam o uso de textos dos filósofos como uma possibilidade de contato direto com o pensador. Essa questão pode ser evidenciada nas falas dos professores que seguem:

\footnotetext{
P6: O original, sempre que possível.

P7: Filosofia é ler texto filosófico ou elaborá-los.

P8: Sim, pois isso possibilita ao aluno o contato direto com o pensamento do autor.

P12: Fundamental para entrar em contato com os originais.

P15: Com os textos filosóficos, os alunos entram em contato efetivamente com os filósofos, suas problematizações e com a História da filosofia por si mesma.

P18: Muito importante, pois eles ajudam os alunos a entrarem em contato com a essência do pensador.

P19: Concede um estreitamento com os clássicos da Filosofia.

P30: Ajuda o estudante a refletir a partir do pensamento do autor. Dá autonomia e desperta no estudante mais interesse pelo tema estudado.
}

Esses exemplos de falas dos professores vão ao encontro do que Severino (2009) apresenta-nos como fonte genuína da Filosofia, que são as fontes primárias que nos convidam a nos guiar. Nos dizeres de Severino (2009):

Ler textos de Filosofia, no âmbito das atividades curriculares da disciplina Filosofia, vai nos fazer sentir a necessidade de um convívio mais amplo com a tradição cultural desta matéria. Seja porque precisamos continuamente consultar as fontes, seja porque precisamos dialogar com os filósofos clássicos e contemporâneos. Por sinal, acontece um relacionamento dialético entre a leitura de textos específicos e o 
Nas falas expostas nesta categoria, fica evidenciada a importância do contato com o pensamento do filósofo. Esse contato possibilita ir muito além daquilo que é apresentado pelos comentadores. Estes contribuem em muito para se pensar a Filosofia, mas também limitam a possibilidade de um contato mais direto com o texto do filósofo.

O contato direto com o texto filosófico exige também que o professor subsidie, conforme Severino (2009), informações históricas e conceituais para que os alunos possam compreender o contexto em que determinado filósofo pronunciou um certo conhecimento. Conforme aponta $\mathrm{P} 15$, anteriormente, o contato direto com os textos filosóficos proporciona aos alunos uma compreensão da História da Filosofia a partir de outras perspectivas.

\section{Categoria IV - Fundamental para a compreensão do aluno}

$\mathrm{Na}$ categoria IV, a importância do uso de textos dos filósofos aparece como uma possibilidade para que o professor ajude o aluno a compreender os conceitos filosóficos de forma clara, conforme evidenciam as falas dos professores a seguir:

\footnotetext{
P2: Fundamental, desde que o professor conduza de forma que o aluno compreenda.

P23: Fundamental, pois são neles que existe o contato com a linguagem filosófica.

P25: Entendo que a utilização do texto filosófico em sala de aula é de suma importância pelo contato direto com o autor e não um comentador ou um livro didático. Os quais, por vezes, impedem a compreensão do aluno sem distorções, em alguns casos, dos termos e conceitos.

P27: É necessário que o aluno esteja em contato com a leitura, pois, além de propiciar o entendimento dos conteúdos que serão trabaIhados em sala, a leitura enriquece o vocabulário, exercita a compreensão e o raciocínio. Estimula também a produção.
}

Mendes e Rezende (2013) utilizam o conceito de mediação praxiológica para especificar que o ensino de Filosofia possui peculiaridades no processo ensino-aprendizagem. Nesse sentido, é necessário considerar a importância da leitura de textos filosóficos como de fundamental importância para que os alunos tenham um contato com as fontes primeiras do pensar filosófico.

As falas dos professores anteriormente apresentadas destacam a importância do contato, da leitura e da compreensão de textos filosóficos em sala de aula para o exercício interpretativo dos textos de Filosofia. Nesse sentido, Horn e Valese (2012) apontam o cuidado para não se cair também em um "textualismo". Nas palavras dos autores: 
Pode-se cair facilmente no textualismo, num reducionismo que implica o risco de entender que a formação filosófica só se dá mediante o domínio técnico dos textos. Não que este domínio não tenha importância, muito pelo contrário, é um dos elementos centrais do processo de apropriação dos conteúdos filosóficos. O problema está em se reduzir à compreensão formal do texto. Portanto, não se trata de descartar a necessidade do domínio técnico do texto, pois quando se está diante do texto filosófico busca-se compreendê-lo a partir de seu contexto. (HORN; VALESE, 2012, p. 169).

Assim, faz-se necessário buscar formas de não cair em um extremismo do textualismo. Isso levaria a perder o foco específico da Filosofia como processo de criação de conceitos.

\section{Categoria V - Entender os conceitos filosóficos como uma construção histórica}

Na categoria $\mathrm{V}$, a importância do uso de texto dos filósofos aparece como uma possibilidade para se entender os conceitos filosóficos como uma construção, conforme evidenciam as falas dos professores que seguem:

P4: Mostrar que o mundo é pensado a milhões de anos pela humanidade e que o que temos hoje é uma construção do que fizemos ontem.

P14: É uma forma de comprovar o que se diz do filósofo diante da problemática.

A fala de P4 aponta o aspecto histórico que a Filosofia carrega em si, e a de P14 aparece como uma forma de se comprovar ou evidenciar, historicamente, o que os filósofos disseram. Já o P3 destaca que é preciso ir aos poucos e sempre relacionar a questão histórica às questões da atualidade:

P3: Acredito ser interessante, no entanto, não no primeiro momento. Assim como a alfabetização, na "filosofação" é necessário ir aos poucos. E, acredito, buscar relacionar a atualidade com os pensamentos dos filósofos a serem apreendidos em sala de aula.

A fala de P32 vai ao encontro da compreensão do papel da Filosofia na sociedade destacada por Jaspers (1971), bem como sobre a importância do uso de textos filosóficos em sala de aula. P32, em sua fala a seguir, destaca que os textos são essenciais, mas que, de certa forma, também precisamos "dar voz" aos filósofos de outras partes históricas.

P32: Os textos são essenciais em sala de aula. Entretanto, precisamos repensar que autores trabalhar. Normalmente, os autores são gregos, romanos, germânicos, italianos, franceses. É preciso dar voz a filósofos que pensar a partir da América Latina, Henrique Dussel, por exemplo. 
O que foi apontado por P32 é de grande importância. Isso talvez seja um grande desafio, porque temos dificuldades em aceitar como filósofos os pensadores que nos são mais próximos. Talvez se estudássemos mais filósofos latino-americanos, dentro do nosso contexto, tivéssemos mais facilidade em relacionar a Filosofia com a vida.

Por fim, conforme P14 nos apresentou, o texto filosófico contribui para pensarmos em suas relevantes contribuições, no sentido de comprovar o que pensamos por meio da tese de um determinado filósofo. Desse modo, poderemos confrontar realidade e pensamento.

\section{Considerações finais}

Neste artigo, tivemos como objetivo analisar as percepções de professores de Filosofia em serviço sobre o uso de textos dos filósofos em sala de aula. Nossos resultados apontam que as suas percepções estão relacionadas a questões sobre o ensino da Filosofia de forma reflexiva, como uma construção histórica e fundamental para que o aluno viva uma experiência filosófica. Os resultados apontaram, ainda, a importância de estudarem os textos filosóficos em sala de aula. Conforme os dizeres dos professores de Filosofia investigados, é de fundamental importância que se busquem metodologias para propiciar uma melhor compreensão dos textos filosóficos.

Ao longo de nossas reflexões, procuramos evidenciar o quanto os referenciais teóricos também nos motivam a utilizar o texto filosófico em sala de aula. $O$ uso de mapas conceituais foi uma das estratégias que encontramos elencadas a fim de possibilitar uma experiência de ressignificar os conceitos filosóficos em sala de aula.

Parece-nos oportuno não negligenciar diversas dificuldades estruturais que são encontradas pelos professores de Filosofia para utilizarem-se de textos filosóficos em sala de aula. Apesar das dificuldades, é muito oportuno que, em algum momento, o docente se utilize de textos filosóficos em sala de aula.

Os resultados da pesquisa com 32 professores de Filosofia nos permitiram inferir que esses docentes estão conscientes da importância do seu compromisso em fazer uso dos textos filosóficos em suas aulas. Assim sendo, em estudos posteriores, pretendemos investigar metodologias para o ensino de Filosofia com textos filosóficos.

\section{Referências}

BARDIN, Laurence. Análise de conteúdo. São Paulo: Edições 70, 2011.

BOGDAN, Robert; BIKLEN, Sari. Investigação qualitativa em educação: uma introdução à teoria e aos métodos. Portugal: Porto Editora, 1994.

GABRIEL, Fábio Antonio. A aula de Filosofia enquanto experiência filosófica. Rio de Janeiro: Multifoco, 2017. 
HORN, Geraldo Balduino; VALESE, Rui. O texto filosófico nas aulas de Filosofia do Ensino Médio: análise e proposição a partir da experiência paranaense. Filosofia e Educação, Campinas, v. 4, n. 1, p. 159-176, abr./set. 2012. DOI: https://doi.org/10.20396/rfe. v4i1.8635442

JASPERS, Karl. Introdução ao pensamento filosófico. Tradução de Leônidas Hegenberg e Octanny Silveira da Mota. São Paulo: Cultriz, 1971.

MENDES, Ademir Aparecido Pinhelli; REZENDE, Edson Teixeira de. O uso de mapas conceituais para leitura de textos filosóficos em sala de aula no Ensino Médio. NESEF - Filosofia e Ensino, Curitiba, v. 3, n. 3, p. 35-48, jun./set. 2013. DOI: http://dx.doi.org/10.5380/nesef. v3i3.54667

NIETZSCHE, Friedrich. Obras incompletas. Tradução de Rubens R. Torres Filho. São Paulo: Abril Cultural, 1978 (Coleção Os Pensadores).

SEVERINO, Antônio Joaquim. Como ler um texto de Filosofia. 2. ed. São Paulo: Paulus, 2009.

\section{Notas}

${ }^{1}$ O presente trabalho foi realizado com apoio da Coordenação de Aperfeiçoamento de Pessoal de Nível Superior (CAPES) - Brasil - Código de Financiamento 001 e com apoio da Fundação Araucária.

\section{Correspondência}

Fábio Antonio Gabriel - Rua Rui Barbosa, 488, Centro, CEP: 86.455-000, Joaquim Távora, Paraná, Brasil.

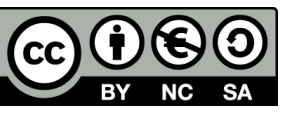

This work is licensed under a Creative Commons Attribution-NonCommercial 4.0 International (CC BY-NC 4.0) 